\section{As autoras respondem}

The authors reply

Las autoras responden

http://dx.doi.org/10.1590/0102-311XCO030616

Andrea Paula Bruno von Zuben \&

Maria Rita Donalísio
Os comentários e reflexões apresentados pelos professores Gustavo Adolfo Sierra Romero e Zélia M. Profeta da Luz destacam pontos de grande relevância sobre o controle da leishmaniose visceral americana (LV) no Brasil.

A revisão crítica da política atual de controle da endemia deve ter como referência evidências científicas fundamentadas na avaliação dos êxitos e fracassos das ações de controle de experiências nos vários cantos do país, como aponta o professor Romero.

A diversidade de contextos epidemiológicos, a deficiente estrutura dos serviços de controle de endemias e insuficientes equipes de saúde nos municípios e estados limitam muitas vezes a execução mínima do preconizado pelo Programa de Vigilância e Controle da Leishmaniose Visceral (PVCLV). A falta de monitoramento contínuo e de registro das intervenções de controle da leishmaniose visceral e de seu impacto (imediato e de longo prazo) deixa "no escuro" a avaliação dos resultados do árduo trabalho de equipes sobrecarregadas pelas constantes urgências em saúde pública no país.

O controle de leishmaniose visceral americana (LVA) tem se revelado como um grande desafio, considerando que tanto as medidas de controle vetorial quanto as medidas dirigidas ao controle da população canina infectada enfrentam importantes problemas na operacionalização no campo.

No Brasil, as campanhas de controle da LVA iniciaram na década de 50, sendo os estados do Ceará e Minas Gerais os principais alvos das atividades. Entretanto, durante a década de 60, as ações foram interrompidas e apenas em 1982 o programa foi retomado, quando a extinta Superintendência de Campanhas de Saúde Pública (SUCAM) detectou um aumento do número de casos de LVA 1. A descontinuidade de ações não ocorreu somente nesse período, a Organização Mundial da Saúde, em 2005, reconheceu como grave a diminuição da capacidade dos países, incluindo o Brasil, na execução de intervenções mais eficazes no controle de doenças vetoriais.

As realidades encontradas nos municípios onde foram realizadas as entrevistas corroboram o achado de que as ações de prevenção e controle são descontínuas, podendo ser afetadas pela priorização de outros programas dependendo da época do ano: por problemas orçamentários e escassez de recursos humanos adequadamente treinados conforme mostrado também por Gontijo \& Melo em 2004 2; pela desorganização de órgãos públicos de saúde com trocas constantes de profissionais, gerando carência de pessoal capacitado para a execução de trabalhos de controle como evidenciado também por Tauil em 2006 3; e pela falta de informação da população e principalmente dos profissionais de saúde.

Como afirma a professora Luz, "no que diz respeito à participação da população há uma lacuna a ser preenchida. Trata-se do empoderamento da população como partícipe ativo do processo de prevenção. É muito difícil que haja participação efetiva da população na resolução de problemas coletivos se de fato esta população não for incluída no processo como protagonista".

A organização centralizada por órgãos e departamentos responsáveis pelas campanhas e programas torna quase inatingível o engajamento da população como protagonista na resolução de problemas 4 . As práticas sanitárias que ganharam hegemonia ao longo do século XX fundaram-se na afirmação da objetividade, da neutralidade e da universalidade do saber científico e nos modelos clássicos de explicação do processo saúde-doença. São pressupostos que sustentam a prescrição de comportamentos tecnicamente justificados como únicas escolhas possíveis para o alcance do bem-estar de todos os indivíduos, independentemente de sua inserção sociohistórica e cultural 5 .

Mesmo naquelas propostas que buscam ampliar a abrangência dos programas educativos, tal ampliação dá-se no sentido da incorporação de estratégias participativas, nas quais a interação com o repertório sociocultural e o seu resgate constituem um recurso de acomodação dos conteúdos técnico-científicos ao universo cultural daqueles a quem se deseja (ou se deve) ensinar 5 .

Como mostrado neste estudo, no caso específico do PVCLV, coloca-se como uma das diretrizes a eutanásia de cães reagentes, sejam eles sintomáticos ou não, tirando-os da casa onde coabitam com as pessoas a despeito da vontade das mesmas. A pessoa que recebe esse tipo de determinação é desconsiderada em seu afeto e desconsiderada na construção de práticas mais democráticas que possibilitariam um maior cuidado do animal, impedindo que este fosse picado pelo mosquito. Nesse contexto, há evidente dificuldade de se realizar a eutanásia canina, uma vez que a sociedade quase sempre se refere ao cão como "um membro da família”. Mais grave 
ainda é que quando esta ação é realizada, ocorre com atraso, perdendo o potencial de impacto esperado na transmissão.

Para que um programa de controle desta natureza fosse realmente efetivo seria necessário respeitar as singularidades da população, as especificidades do território atingido por meio de formatos dialógicos e participativos que envolvessem os profissionais de saúde e a comunidade, e contribuíssem para o diálogo entre a ciência e o senso comum.

Por outro lado, lacunas do conhecimento sobre a cadeia causal de casos graves, a abordagem diagnóstica ainda insuficiente e pouco específica, dificuldades no tratamento de cães e humanos, revelam a necessidade de atualização das medidas preconizadas à luz de evidências científicas e experimentadas em outras regiões do planeta. Todas essas lacunas podem explicar a precariedade dos resultados observados até o momento em termos dos indicadores de resultados, quais sejam: redução da incidência e da letalidade da doença humana, como afirma Gustavo Romero.
O esgotamento das medidas de controle e o pequeno impacto na incidência da doença exigem reflexão crítica sobre o PVCLV. Entre elas investimento contínuo e sustentável em medidas pautadas em saneamento ambiental que sejam capazes de diminuir matéria orgânica que possa servir como criadouro do vetor; em controle químico com o uso de aplicação estratégica de inseticida de poder residual, com vistas à interrupção de transmissão; em medidas voltadas ao reservatório canino que envolva a proteção dos animais contra a picada de insetos (uso de coleiras inseticidas ou outros produtos que impeçam o repasto sanguíneo do vetor no cão, bem como levar em consideração vacinação e tratamento que diminuam a carga parasitária e o poder infectante do animal ao vetor); e em ações de educação em saúde que permitam tornar participantes diversas camadas da população e democratizar o conhecimento e as incertezas sobre as práticas de controle.
1. Alves WA, Bevilacqua PD. Reflexões sobre a qualidade do diagnóstico da leishmaniose visceral canina em inquéritos epidemiológicos: o caso da epidemia de Belo Horizonte, Minas Gerais, Brasil, 1993-1997. Cad Saúde Pública 2004; 20:259-65.

2. Gontijo CMF, Melo MN. Leishmaniose visceral no Brasil: quadro atual, desafios e perspectivas. Rev Bras Epidemiol 2004; 7:338-49.

3. Tauil PL. Perspectivas de controle de doenças transmitidas por vetores no Brasil. Rev Soc Bras Med Trop 2006; 39:275-7.
4. Teixeira CF, Paim JS, Vilasbôas AL. SUS, modelos assistenciais e vigilância da saúde. In: Rozenfeld S organizadora. Fundamentos da vigilância sanitária. Rio de Janeiro: Editora Fiocruz; 2000. p. 49-60.

5. Meyer DEE, Mello DF, Valadão MM, Ayres JRCM. "Você aprende. A gente ensina?" Interrogando relações entre educação e saúde desde a perspectiva da vulnerabilidade. Cad Saúde Pública 2006; 22:1335-42. 